\title{
Pênfigo: uma cartografia sobre as articulações das políticas em saúde
}

\author{
Pemphigus: cartography on the coordination of health policies
}

Diego Alexandre Rozendo da Silva ${ }^{1}$

Anita Guazzelli Bernardes ${ }^{1}$

${ }^{1}$ Universidade Católica Dom Bosco. Av. Tamandaré 6000, Jardim Seminário. 79117-900 Campo Grande MS Brasil. diegosilva.alexandre@ gmail.com

\begin{abstract}
Pemphigus is a group of autoimmune blistering diseases that affect the skin and mucous membranes, the global incidence of which is 0.75 to 5 / 1.000.000 cases a year. The approach taken derives from the relations of power/truth and subjectivity that produce modes of experience from the perspective of hospitals and public policies. It involves cartographic qualitative research, supported from a Deleuzian standpoint. The objective was to discuss pemphigus as a chronic disease and discuss health policies and their impact on care practices. This cartography was conducted in a philanthropical hospital, which is a national reference for the treatment of pemphigus. The research was conducted from September 2012 to February 2013. The analysis of materials included: medical records, field diary reports of all healthcare activities, such as medical consultations, technical procedures performed by nursing staff and medical staff and reports of patients, families, physicians, and nursing staff. The analyses were created from a Foucauldian historical and genealogical perspective. The conclusion reached is that health policies for chronic patients with pemphigus are not presented as a condition to be avoided / prevented, but as abnormal groups and bio identities that have no effect on the whole population.
\end{abstract}

Key words Pemphigus, Cartography, Public policy
Resumo Pênfigos são um grupo de doenças bolhosas autoimunes que acometem a pele e mucosas, cuja incidência mundial é de 0,75-5/1.000.000 casos ao ano. Nossa problematização parte das relações de poder/verdade e subjetivação que produzem modalidades de experiência sob a perspectiva hospitalar e das políticas públicas. Pesquisa qualitativa cartográfica, sustentada sob uma perspectiva Deleuziana. Nossos objetivos foram problematizar o pênfigo como doença-crônica e discutir as politicas de saúde e sua repercussão nas práticas de cuidado. Percorremos esta cartografia em um hospital filantrópico de referência nacional para tratamento de pênfigo. Esta pesquisa foi construida de setembro de 2012 a fevereiro de 2013. Os materiais de análise foram: prontuários, relatos em diário de campo de todas as atividades assistenciais realizadas, tais como: consultas médicas, procedimentos técnicos realizados pela equipe de enfermagem e equipe médica e relatos de pacientes, familiares, médicos, e equipe de enfermagem. Nossas análises foram construídas sob uma perspectiva histórico-genealógica Foucaultiana. Consideramos que as políticas de saúde a doentes crônicos com pênfigo não se apresentam como uma condição a ser evitada/prevenida, mas como uma anormalidade de grupos, bioidentidades que não têm efeito no conjunto da população.

Palavras-chave Pênfigo, Cartografia, Políticas públicas 


\section{Introdução}

O pênfigo é uma doença autoimune que se manifesta pelo aparecimento de bolhas na pele. A população de risco para a doença constitui-se de trabalhadores rurais, pessoas que moram e trabalham em zona endêmica. Não há predomínio de sexo, grupo racial ou étnico. Afeta crianças e adultos jovens, com pico de incidência entre a segunda e a terceira década de vida. A população afetada vive em casas rústicas, distando 10 a $15 \mathrm{~km}$ de grandes rios ou enseadas, e a doença pode afetar vários membros da mesma família. Atualmente, o pênfigo é endêmico em certos estados brasileiros, com predominância na região centro-oeste. E até o momento sua etiologia é desconhecida ${ }^{1}$.

Existem dois tipos clínicos mais frequentes de pênfigo, o vulgar e o foliáceo ${ }^{2}$. No pênfigo vulgar, a acantólise ocorre na camada basal, podendo acometer pele e mucosas, considerada a forma clinicamente mais grave, cuja incidência mundial é de 0,75-5/1.000.000 casos ao ano. No pênfigo foliáceo, a acantólise ocorre abaixo da camada córnea, ou seja, mais superficial, raramente acometendo a mucosa $a^{2,3}$. A variante vulgar é relativamente rara, ocorre mais frequentemente após os 40 anos, acometendo ambos os sexos.

O pênfigo foliáceo possui as mesmas características epidemiológicas do vulgar em todas as partes do mundo, entretanto, no Brasil possui aspectos epidemiológicos endêmicos distintos, com elevada frequência na zona rural de alguns estados brasileiros. E possui provável conotação genética, com frequência familiar de $12 \%$ dos casos $^{2}$.

As pesquisas existentes sobre a temática limitam-se a análises epidemiológicas e técnicas de manejo farmacológico.

No entanto, neste estudo buscaremos privilegiar as articulações do pênfigo no campo das políticas públicas de saúde para seus pacientes, onde infelizmente são escassas as pesquisas e iniciativas políticas. Este campo de análise permitiu a construção de ferramentas que orientaram o percurso da investigação não em termos de busca de evidências, mas de problematização das relações políticas em saúde e o pênfigo.

Acredita-se que este estudo possa contribuir para a fundamentação de próximos olhares, norteando o atendimento público de saúde a pacientes com pênfigo, além de favorecer a produção de novas questões de pesquisa.

\section{Percurso metodológico}

Trata-se do recorte de uma pesquisa qualitativa, de metodologia cartográfica, sustentada teoricamente sob uma perspectiva pós-estruturalista da psicologia social. Como orientação metodológica utilizamos a cartografia apresentada por Gilles Deleuze, pois em tal método compreendemos a pesquisa cartográfica como uma prática performativa, ou seja, que se faz com o outro e não sobre o outro, isto indica que para saber como é viver com pênfigo é preciso acompanhar este processo em ação, se fazendo na prática cotidiana daquelas pessoas que o vivenciam ${ }^{4,5}$.

A cartografia é proveniente de esforços teóricos dos autores Deleuze e Guattari ${ }^{6}$, que trabalharam a construção e a desconstrução de certas formas de pensar as estruturas do conhecimento, apresentado na perspectiva da multiplicidade de atos e fatos e girando no reconhecimento dos rizomas que são conceituados como o processo de construção do conhecimento humano, na busca pelo potencial da diferença ${ }^{5,7}$.

A atitude de pesquisa cartográfica é apresentada por Gilles Deleuze como algo territorial e coletivo, tem-se uma atitude coletiva porque é relacional; é político, porque envolve interações entre forças; tem a ver com uma ética, porque parte de um conjunto de critérios e referências para existir; e tem a ver com uma estética, porque é através dela que se dá forma a esse conjunto, constituindo um modo de expressão para as relações, uma maneira de dar forma ao próprio território existencial. Por isso, pode-se dizer que a cartografia é um estudo das relações de forças que compõem um campo específico de experiências, que se constitui no agenciamento entre: usuários e profissionais de saúde, instituições, procedimentos clínicos, diagnósticos, territórios etc., ${ }^{7.8}$.

Diante de tal processo me coloco na posição de cartógrafo no campo das relações intersubjetivas em saúde. O território existencial que percorremos foi um centro hospitalar filantrópico, na unidade dermatológica considerada referência nacional no tratamento de pênfigo no Brasil, realizando tais atividades há mais de 60 anos, o referido hospital está situado na cidade de Campo Grande, Mato Grosso no Sul.

Para ambientação e aculturação no território realizamos quatro encontros semanais de 6 horas de duração, entre os meses de setembro de 2012 e fevereiro de 2013.

Durante este período e após ele, realizávamos discussões mensais para a construção das análises entre um grupo de pares revisores pós-gra- 
duandos e doutores com expertise em pesquisa cartográfica, para que nesta medida, pudéssemos ampliar as possibilidades de observação, sentidos e agenciamentos para a construção de "rizomas", na busca pelo potencial da diferença.

Nossos objetivos foram problematizar o pênfigo como doença-crônica e discutir as políticas de saúde e sua repercussão nas práticas de cuidado.

Os materiais de análise foram: prontuários, relatos em diário de campo de todas as atividades assistenciais realizadas, tais como, consultas médicas, procedimentos técnicos realizados pela equipe de enfermagem e equipe médica, bem como, relatos de pacientes, familiares, médicos, e equipe de enfermagem.

Neste sentido, obtivemos uma amostra variada de participantes, 2 (dois) médicos dermatologistas, 2 (dois) enfermeiros, 6 (seis) técnicos de enfermagem e 11 (cinco) pacientes diagnosticados com pênfigo, totalizando 21 participantes.

Durante este período de 6 meses de ambientação e aculturação foram oportunizados mais de 90 (noventa) encontros, antes deste período apresentamos nossos objetivos de pesquisa, e após assinatura de termo de consentimento livre e esclarecido. Tais relações com pacientes e equipe se deram na construção de vínculos, pois permeamos o território de vivências observando e cartografando as relações estabelecidas entre pacientes, equipe de enfermagem e médicos. Estas observações e diálogos foram agenciados informalmente, ou seja, sem roteiro previamente estabelecido.

Este percurso nos levou a tematizar sobre o devir existencial do pênfigo - devir existencial, assim como nos apresenta Deleuze e Guattari ${ }^{7}$, trata-se de lançar nossos olhares sobre todo um sistema de produção de sentidos e significados que delimitam a experiência de ter/ser pênfigo tal atitude nos levou a teorizar três perspectivas cartográficas, após análise de todo o material coletado, sendo elas: Pênfigo - primeiros indícios; Pênfigo - construções e práticas existenciais; e, Política de saúde - pênfigo como superfície de investimentos.

\section{Resultados e discussões}

\section{Pênfigo: primeiros indícios}

Peço licença ao leitor para aqui tentar, de certa forma, elucidar algumas questões referentes às trajetórias de vida dos sujeitos deste estudo.
Em nossos encontros neste território de existências podemos analisar que as questões do médico, o discurso do paciente e as observações conduzidas nestas relações acabam por construir um "ser pênfigo". Como é que o encenam? Iremos apresentar de modo genérico como se dá esta vivência e seus primeiros indícios.

$\mathrm{O}$ paciente em sua primeira consulta refere bolhas que pensa ele ser de um impetigo (doença cutânea de origem bacteriana), mas esta bolha dói como uma queimadura (P9), elas se manifestam no tronco, face, couro cabeludo e com o tempo surgem nos membros superiores e inferiores. Após estes sintomas, os pacientes buscam os serviços de uma unidade básica de saúde próxima a sua casa, em alguns casos são prescritos antiinflamatórios, mas não ajudou de nada este remédio lá no posto, eles não sabem o que é de verdade (P3). Ele percebe que as lesões e as dores se acentuam quando fica exposto ao sol, eu tive que parar de trabalhar, sou pedreiro, fico no sol o dia todo, doía muito mesmo isso ( $\mathrm{P} 4)$. Se o paciente não é rapidamente diagnosticado, começam sistemas de febre, as bolhas crescem, aparecem em outros locais. Eu achei que ia morrer, me dava calafrio, tomava o negócio pra baixar a febre, mas nada de resolve (P3). Nesta medida, os pacientes retornam ao serviço de saúde, que acaba por referenciá-los a um serviço hospitalar, e após muitas semanas ele é encaminhado a um serviço especializado. Eu fiquei muito tempo sem saber o que acontecia comigo, o que eu tinha ninguém sabia certo mesmo (P5) Todo este percurso é acompanhado de uma inquietação: o que eu tenho?

$\mathrm{E}$ ao chegar em um serviço especializado a resposta biomédica poderá ser inscrita através de conjunto de sintomas visíveis, com queixas que podem ser articuladas por um doente, esta performance clínica do pênfigo precisará ser traçada.

Para tanto, a pergunta que se faz não é "o que é o pênfigo?" Mas de que modo certas práticas o produzem? Independentemente da resposta que possa ser definida, caso se ponha a questão, aquilo que acontece quando observamos este domínio das práticas é que o pênfigo parece ser performado de muitas maneiras diferentes.

Descreve-se aqui três destas maneiras, desveladas pelos autores, que inscrevem o pênfigo sob planos de visibilidades, e ao acompanhar os procedimentos de diagnóstico e internação pode-se perceber toda uma tecnologia biomédica empregada sobre este corpo ${ }^{9}$. Primeiro: no consultório um doente queixa-se de bolhosas, que ao romperem ao menor contato causam dores semelhantes à de uma queimadura. $\mathrm{O}$ médico quer saber 
mais, quando e como se manifestam os sintomas? Aproxima-se então do doente, analisa sua pele, qual o tamanho das lesões? Qual o local das lesões? Apresentam sangramento? Ou infecção? Que aspecto geral tem a pele, verifica-se o sinal de Nikolsky - que consiste no descolamento epidérmico de pele perilesional após fricção. Temos aqui uma queixa que é perpassada por um saber biomédico para a construção do diagnóstico clínico.

E onde podemos dar possibilidade de uma relação que faça existir uma expressão subjetiva das vivências? Angustia, isolamento social, medo, sentidos associados a uma percepção estética de "deformidade". Durante um dos encontros (P6) diz: [...] depois que me casei tive as bolhas, me senti deformada, tinha medo que meu marido fosse me largar, tinha medo de sair de casa, nunca havia falado isso antes, ninguém nunca me pergunto.

Percebemos que o pênfigo, enquanto saber de doença autoimune, também representa um conflito identitário biológico, onde o corpo "desconstrói" o próprio corpo, onde as bolhas se inscrevem, no lugar onde a nossa identidade é mais profunda: a pele.

Tais possibilidades de expressão dificilmente são oportunizadas, notamos nesta medida um sistema que semelhante a outros de atenção a saúde está limitado a delimitação de diagnósticos e medidas farmacológicas de manejo.

A segunda perspectiva desvelada diz respeito às rotinas laboratoriais, sabe-se que o pênfigo pode ser diagnosticado por meio de técnicas histopatológicas e de imunofluorescência, mostrando a presença de anticorpos IgG, tanto na pele quanto na circulação sanguínea dos enfermos, dirigidos contra os espaços intercelulares da epiderme ${ }^{10}$. Acompanhamos tais exames e os índices de normalidade/anormalidade de IgG são comparados e o diagnóstico é desenhado. Os pacientes não são admitidos na internação sem que esta ferramenta diagnóstica seja empregada.

Deste modo os saberes biomédicos vão compondo um saber e um viver em relação ao ser/ ter pênfigo, onde os sujeitos são apenas perpassados por estas práticas. Percebemos tais relações na fala de (P5), quando diz olha, um pedaço da minha pele foi para o laboratório, a moça da enfermagem veio aqui e me disse que tinha que me levar para o laboratório, eles coletaram um negócio e depois disseram que era pênfigo mesmo.

Apreende-se, portanto, que ter pênfigo não é algo que uma pessoa é em si mesma, mas algo que ela se torna, quando articulada em certas práticas, em sua maioria inscritas sobre um saber biomédico.
E então temos a terceira perspectiva, os aspectos socioambientais. Estudos demonstram que existem possíveis agentes ambientais no envolvimento do Pênfigo Foliáceo Endêmico, uma delas é a relação com a picadura de "borrachudos". Em um dos primeiros estudos epidemiológicos do grupo cooperativo do fogo selvagem, foi reportado que picaduras de simulídeos (borrachudos) eram 4,7 vezes mais frequentes em indivíduos com Pênfigo Foliáceo Endêmico do que em controles. O Simulium nigrimanum foi detectado como sendo a espécie predominante em área de alta prevalência do $\mathrm{PFE}^{10}$.

Tais estudos reportam que exposição do doente a outros fatores ambientais, tais como outros insetos hematófagos (triatomídeos e cimecídeos) e moradias rústicas, com tetos de sapé e paredes de adobe mostram-se relevantes no desencadeamento do Pênfigo ${ }^{10}$.

A caracterização da identidade socioambiental como registro sobre o corpo parece se estabelecer neste grupo, observamos que em todos os primeiros atendimentos o inquérito em relação ao local de moradia era um dos itens que compunham o diagnóstico descrito nos prontuários, notamos que todos os indivíduos diagnosticados com pênfigo eram moradores de áreas rurais, ditas endêmicas para pênfigo, eram eles: agricultores, pedreiros, marceneiros e donas de casa.

Portanto, nesta terceira performance indagamos a produção de uma possível "ecoidentidade" ou Oikos-identidade. Oikos, palavra grega cuja tradução literal em português significa "casa" e que dá origem ao prefixo "Eco", de nossa língua, ou em termos de territórios existenciais, uma possível "identidade de casa".

E este corpo de estranhamentos internos, de uma pele que não se fecha, projeta-se socialmente em um registro de "casa", mas não apenas de uma casa em termos de residência, mas de uma habitação identitária, sua pele, seu corpo.

Pele que retém, contém em suas características internas e externas diversas "marcas" de relação, sejam elas advindas de um inquérito clínico, laboratorial ou socioambiental. Como nos diz Deleuze $^{11}$ : "o interior e o exterior, o profundo e o alto, não têm valor biológico a não ser por esta superfície topológica de contato. É, pois, até mesmo biologicamente preciso compreender que o mais profundo é a pele".

Esta subjetividade se produz na relação das forças que atravessam o sujeito, no movimento, no ponto de encontro das práticas e nas formas de reconhecimento de si.

$O$ pênfigo enquanto experiência apresenta-se como um corpo que é aberto biologicamente ou 
dermatologicamente ao "fora", onde o limiar de corpo é invadido.

Estes três indícios acabam por compor uma experiência de ser/ter pênfigo não apenas ancoradas sobre uma materialidade clínica, estatística ou socioepidemiológica, estes saberes apresentaram-se como frágeis ao conduzir os saberes com o pênfigo.

Percebemos que este corpo que fala mais sobre uma dimensão de uma estética da existência, do corpo como plano de superfície e de contato social, de enfrentamento, onde a prática clínica e epidemiológica não atendem mais as demandas de um ser humano que possui necessidades interdependentes, que diz: Enfermeiro é hoje que eu vou morrer? ... nada vai mudar essa realidade, viver em hospital e trancada em casa com medo de tudo não é vida! (P10). Considera-se, assim, que este ser humano fala através de uma prática existencial com o pênfigo, algo que lhe foi transmitido como verdade inquestionável sobre o seu viver, pois as possibilidades de vida e de ser estão ancorados sob um saber limitador de existência de doença.

\section{Pênfigo: construções e práticas existenciais}

Buscamos apresentar como um passo fundamental para a compreensão estética do pênfigo, ou seja, um território existencial, como uma construção de realidade de doença que é feita, localizada histórica, cultural e materialmente, e que também é múltipla ${ }^{9}$.

Mas para que tal encontro seja percorrido é necessário partir de uma prática, como um conjunto de revezamentos de uma teoria a outra, e a teoria sobre um revezamento de uma prática a outra. Nenhuma teoria pode se desenvolver sem encontrar uma espécie de muro e é preciso a prática para atravessar o muro ${ }^{12}$.

As ferramentas conceituais foucaultianas como: verdade, poder e subjetividade que produzem uma estética da existência, mas também formas de governo dos vivos, são reveladas nesta prática de pensamento para cartografar com os pacientes com pênfigo, serão utilizados estes elementos para que o "muro possa ser atravessado", como nos diz Foucault ${ }^{12}$.

Estas ferramentas conceituais permitiram delimitar tais referenciais foucaultianos, no que se refere à verdade, apresentada como "indissociável da singularidade do acontecimento"13. Aquilo qualificado de verdadeiro não habita num já-aí, antes, é "produzido como acontecimento num espaço e num tempo específico"13.
Os discursos produzidos por estas relações de poder na instituição hospitalar são articulados na fala do paciente, que diz: não posso mais fazer $o$ que quero, não posso comer o que quero, se não a doença ataca, o médico disse que se eu quiser ficar bom vou ter que fazer isso, então vou fazer né, fazer o que? Vou tentar passar por cima disso (P3).

Tal fala é produzida, pois durante a internação que leva em média 30 (trinta) dias os pacientes eram medicados diariamente com corticoides, especialmente prednisona. Um dos efeitos desta medicação é o aumento do apetite. A fala acima é articulada mediante uma prática de poder/saber biomédico performada pela equipe de enfermagem que coíbe o consumo exagerado de alimentos, valendo-se do discurso: o médico disse [...].

As práticas curativas podem, nesta medida, ser apresentadas como um campo de biopoder, como um desdobramento de modalidades somatizantes, de subjetividade, pois temos recorrido cada vez mais para explicações que enfatizam características biológicas dos comportamentos e atitudes humanas ${ }^{14}$.

Pois quando nos referenciamos nas estratégias de biopoder passamos a falar sobre nós e a agir uns com os outros a partir da pressuposição de que nossas características são preponderantemente formatadas pela biologia, mas, principalmente, este biopoder pelo qual somos interpelados irá tratar de um investimento na vida, nas formas de viver, com tecnologias disciplinares e regulativas que encontram no biológico um foco privilegiado de suas estratégias de investimento ${ }^{15}$.

Tais marcas de investimento biológico são desveladas ao ouvir de uma enfermeira Sabe, tenho pacientes aqui que tem a doença a mais de 10 anos, e tem recidiva sempre, acho que eles não seguem as instruções em casa, acho que não tomam a medicação direito, daí volta para cá, a maioria dos pacientes internados já esteve antes, mas parece que não aprendem (E2).

Esta visibilidade científica se faz sobre o corpo [...] que não aprende, com marcas de bolhas de pênfigo que se inscrevem na pele como patológicas, e que são apresentadas como verdades acerca de diagnosticar e tratar este corpo, que será submetido a práticas curativas que foram "validadas" novamente pela prática médica.

Portanto, esta análise compreende as relações de poder estabelecidas nas instituições, seja na família, nos hospitais, na escola, marcadas pela disciplina e pela norma, passíveis de práticas curativas e submissas politicamente ${ }^{12}$.

Mas também buscamos a produção de um fazer viver, de um modo de regulação da vida 
da população em seu conjunto, esta regulação se dá no corpo que é "classificado", mediante um questionário epidemiológico, e que será cuidadosamente isolado em uma unidade de internação hospitalar específica, com outros pacientes que tem a mesma doença, onde as práticas políticas e curativas serão controladas, seja na dieta, repouso, período de internação, tipo de curativo ou uso de medicamentos ${ }^{16}$.

Com este sentido amplo, a política, ou seja, este processo de modelação ativa, como caracteriza $\mathrm{Mol}^{9}$, é a forma de atividade humana que, ligada ao poder, coloca em relação sujeitos, articula-os segundo regras ou normas não necessariamente jurídicas e legais. Não mais pensada exclusivamente a partir de um centro do poder (o Estado, uma classe), a política se faz também em arranjos locais, por microrrelações, indicando esta dimensão micropolítica das relações de poder ${ }^{12}$.

E nestas práticas de constituição de si, precisamos caminhar sobre algumas pistas histórico-políticos em medicina e saúde, pois o reflexo destes efeitos de verdade sobre pênfigo começam a ser ampliados nesta cartografia, onde estas construções de performances também foram possíveis mediante um discurso biomédico que foi produzido cultural e historicamente, no escopo de políticas públicas em saúde.

\section{Política de saúde: pênfigo como superfície de investimentos}

Durante esta construção de saberes com pacientes com pênfigo, nos foi referido por um médico do serviço, mediante suas impressões sobre o sistema público de saúde nos diz: só existirá interesse público quando a doença afetar a maioria da população, quando eles estão na UBS eles não recebem a Prednisona pelo governo, medicação indispensável para este tratamento, em muitos momentos temos que recorrer a defensoria pública para que os pacientes possam ter acesso a medicação gratuitamente (M1).

Para ele as estratégias de tratamento disponíveis na rede pública de saúde não eram compatíveis com as necessidades clínicas dos pacientes e por vezes era necessário recorrer a instâncias jurídicas para que os casos pudessem ser atendidos.

Portanto, pode-se entender, mediante tal fala, que existirá interesse quando os processos econômicos forem afetados, ou seja, apenas quando a doença começar a interferir na produção da população. E quando não temos subsídios médicos, farmacológicos e tecnológicos que dizem o que é a verdade sobre o pênfigo, deve-se deixar morrer?
Através de uma análise pós-estruturalista podemos considerar a saúde pública como uma das responsáveis pela construção de uma nova estrutura urbana, pela produção de estratégias preventivas e de interiorização das responsabilidades sobre o corpo.

É inegável que seus diferentes discursos se fundam no naturalismo médico, que, invocando cientificidade, legitimou a crescente medicalização do espaço social, ou seja, deve-se combater as epidemias e as endemias, esquadrinhando o espaço urbano com dispositivos sanitários, e se constituiu como estratégia dominante da saúde pública.

As epidemias representaram o campo privilegiado para a produção, a reprodução e a diversificação da medicalização do campo social, com o fortalecimento correlato do poder da medicina. Entretanto, a caução científica do discurso naturalista da medicina sempre colocou entre parênteses a dimensão política das práticas sanitárias. Em nome do discurso da ciência, legitimam-se práticas de marginalização de diferentes segmentos sociais ${ }^{17}$.

Muitos pacientes usuários do sistema de saúde pública acabavam por se sentir marginalizados quando o acesso à saúde lhes era impossibilitado Ninguém sabe como tratar da minha doença na minha cidade, eles não tem medicação, o médico não sabe o que falar para mim lá no postinho, ele diz apenas que é para eu fazer o que os médicos do hospital me mandaram fazer, só isso, a gente não é ninguém lá (P8).

Notamos aqui uma prática do direito de fazer viver e de deixar morrer, é evidente que existe uma importância do conhecimento sobre as populações, para que nessa medida possam ser criadas estratégias para se estabelecer formas de governo, no entanto, o governo que se apresenta para este paciente é aquele que limita o acesso e que inscreve este sujeito em um local de marginalização, pois o mesmo não responde ao perfil epidemiológico passível de atendimento em uma unidade básica, nesta prática se relacionam pobreza, perigo e epidemiologia.

Notamos tal condição de deixar morrer na fala do paciente que diz: [...] eles não dão a medicação (prednisona), fiquei muito doente, tive infecção de pele, quase me mataram (P2).

Tal enunciação se refere ao poder sobre a população exercido pelos dispositivos de segurança que são produzidos pela biopolítica e como forma de governo sobre os outros que se exercem através de tecnologias de governo sustentados pela produção de saberes biomédicos ${ }^{18}$. 
Nesse sentido, o conceito de governamentalidade apresentado por Foucault ${ }^{18}$ constitui um instrumento crítico de uma sociedade gerenciada pelos ideais neoliberais, agindo sobre a população através de dispositivos de segurança que limitam e controlam suas escolhas, desejos, comportamento, mobilidade, saúde, alimento, enfim, a vida do indivíduo.

Para que se possa ter uma amplitude de entendimento sobre os processos de atenção à saúde de pessoas com doença crônica usemos a definição do Ministério da Saúde ${ }^{19}$ que considera doença crônica como: as doenças cardiovasculares, as neoplasias, as doenças respiratórias crônicas e a diabetes melito. E também são incluídas nesse rol aquelas doenças que contribuem para o sofrimento dos indivíduos, das famílias e da sociedade, tais como as desordens mentais e neurológicas, as doenças bucais, ósseas e articulares, as desordens genéticas e as patologias oculares e auditivas.

Nota-se que o Ministério da Saúde ${ }^{19}$ inclui a noção de ...doenças que contribuem para o sofrimento dos indivíduos, das famílias e da sociedade... Analisamos neste trecho as condições deste biopoder que mediante uma estratégia biopolítica permite legitimar a existência de práticas de controle dos indivíduos e da população em nome do "bem comum", da saúde e do vigor das populações.

Tais enunciações nos remetem a um projeto de sociedade, ou seja, uma forma de habitar, de quem pode habitar e de que modo ${ }^{20}$.

Este tipo de prática de governo ora controla a vida, ora exclui certos viventes da lógica de funcionamento da própria sociedade. Agamben ${ }^{21}$ nos apresenta um novo paradigma de governo, o Estado de Exceção. Para pensar esse Estado de Exceção como paradigma de governo, ele parte da ideia de que, na atualidade, o governo se exerce sempre produzindo exceções e, nessa exceção, ele suspende a norma, fazendo valer de forma arbitrária a sua autoridade. Assim como relatado por M1 temos que recorrer à defensoria pública para que os pacientes possam ter acesso à medicação gratuitamente.

Estes saberes perpassam a política ocidental e encontram, na modernidade, sua máxima saturação. Sua reflexão político-filosófica se estabelece em uma nítida correlação entre a prática do soberano e o exercício de governo no Estado moderno, identifica-se tais saberes ao depararse com a enunciação: só existirá interesse público quando a doença afetar a maioria da população [...] (M1).
Nesta cartografia do pênfigo acessou-se o Plano de Ações Estratégicas para o Enfrentamento das Doenças Crônicas Não-Transmissíveis (DCNTs) no Brasil, trata-se de um plano que terá um período de investimentos de 10 anos de 2011 a 2022, e que retrata tais fenômenos biopolíticos ${ }^{19}$.

O manual do Ministério da Saúde ${ }^{19}$ apresenta que os custos diretos das DCNTs para o sistema de saúde representam impacto crescente. No Brasil, as DCNTs estão entre as principais causas de internações hospitalares. Recente análise do Banco Econômico Mundial estima que países como Brasil, China, Índia e Rússia perdem, anualmente, mais de 20 milhões de anos produtivos de vida devido às DCNTs.

Estimativas para o Brasil sugerem que a perda de produtividade no trabalho e a diminuição da renda familiar resultantes de apenas três DCNT (diabetes, doença do coração e acidente vascular encefálico) levarão a uma perda na economia brasileira de US $\$ 4,18$ bilhões entre 2006 e $2015^{19}$.

As intervenções para prevenção e controle de DCNT incluem diversas ações, que têm sido monitoradas e avaliadas por meio de vários estudos, mas é comum ao analisarmos as políticas de saúde os termos serem essencialmente estatísticos, as estratégias são traçadas mediante a relação de impacto econômico, característica de uma biopolítica e onde ficam os demais sujeitos que não são legitimados pelo impacto econômico ou epidemiológico de suas experiências?

Me afastei do trabalho, sou agricultor, trabalho para uma empresa, passou o limite do meu atestado, tive que dar entrada no INSS, depois de 30 dias o meu dermatologista disse que não podia trabalhar, se não as bolhas poderiam aumentar e doer mais, mas o médico na perícia disse que eu podia trabalhar sim, e daî?! Vou passar fome, minha esposa esta trabalhando, mas e quando as coisas acabarem, não posso morrer de fome (P8).

O pênfigo, enquanto fenômeno epidemiológico, não possui a mesma expressão populacional que a diabetes, doenças cardiovasculares, entre outras, mas temos experiências e vivências que precisam ser atendidas nesta realidade de vida, e estas práticas precisam ganhar contornos de intervenção em todas as esferas de assistência em saúde.

Semelhantemente, a Organização Mundial da Saúde (OMS) divulgou as intervenções consideradas mais custo-efetivas, sendo algumas delas ainda consideradas as "melhores apostas" (ações que devem ser executadas imediatamente para que produzam resultados acelerados em termos de vidas salvas, doenças prevenidas e custos altos evitados) $)^{22,23}$. 
Todas estas "melhores apostas" previstas pelo ministério da saúde nas DCNTs são ilustradas no slogan do Portal on-line do Governo Federal cuja imagem é composta por um guarda-chuvas, feito com a bandeira nacional, "protetor" de diversas doenças crônicas.

Esta proteção será conferida, se você cuidar de seu corpo, mantendo-se saudável, pois nesta medida, você evitará doenças como diabetes, hipertensão, obesidade e etc. ${ }^{24}$. No entanto, a questão que apresento é: "E quando a DCNT é autoimune? Estou sob o guarda chuva da política pública de saúde que deveria garantir meu acesso à saúde?”

A racionalidade da saúde perfeita nos leva a crer que um corpo fora dos padrões de autocontrole tem origem em uma falta de manejo de si próprio. quando eu falei que tinha pênfigo minha irmã de perguntou: O que você fez? Isso é contagioso? E agora, vou poder lhe visitar?, ela falava como se eu fosse uma leprosa? (P2).

Ao analisarmos o Plano de Ações Estratégicas para DCNTs, é conveniente fazermos uma discussão que a correlaciona à possibilidade do fazer viver para aquelas endemias/epidemias passíveis de prevenção, mas, e para aquelas em que isso ainda não é possível? Tornam-se fantasmas, invisíveis no campo da política pública de investimento na vida, como refere Foucault, "uma vida dos homens infames". Infames estes que não terão a proteção do "guarda-chuva" de políticas em saúde ${ }^{25,26}$.

O Ministro da Saúde ${ }^{19}$ sublinhou que o objetivo do plano de enfrentamento de DCNTs é o de promover o desenvolvimento e a implementação de políticas públicas efetivas, integradas, sustentáveis e baseadas em evidências para a prevenção e o controle das DCNT e seus fatores de risco e fortalecer os serviços de saúde voltados às doenças crônicas. O plano aborda os quatro principais grupos de doenças (circulatórias, câncer, respiratórias crônicas e diabetes) e seus fatores de risco em comum modificáveis (tabagismo, álcool, inatividade física, alimentação não saudável e obesidade) e define diretrizes e ações em: a) vigilância, informação, avaliação e monitoramento; b) promoção da saúde; c) cuidado integral.

Esta é uma performance da política de saúde para quem o pênfigo não se apresenta como um perigo a ser evitado/prevenido, mas como uma anormalidade de grupos que não tem efeito no conjunto da população, como infames da história que só aparecem nesses breves contatos com o poder, ou seja, quando dentro do hospital.

No que diz respeito a medidas de acesso ao sistema de saúde, vemos pacientes que não con- seguem assistência adequada, que peregrinam por unidades de saúde e hospitais sem assistência integral a suas necessidades.

Não foram encontradas estratégias direcionadas a esta população, articuladas de modo propositivo pela secretaria de saúde do estado, os índices de incidência e de atendimento nos serviços de saúde não estão relacionados em nenhuma base do governo. Ou seja, os pacientes com pênfigo são como "fantasmas" no sistema.

Nas poucas oportunidades em que se dedica a transcender o diagnóstico biopolítico do presente, Agamben ${ }^{27}$ reflete sobre a noção de "forma-de-vida", isto é, de uma vida que não pode dissociar-se de sua forma, que não pode jamais ser apreendida como vida nua, pois, em seu viver, em seus atos e comportamentos, nunca se trata simplesmente de meros "fatos", mas sempre de "possibilidades de vida", sempre e antes de tudo de potências, nenhum comportamento e nenhuma forma de vida humana jamais são prescritos por uma vocação biológica específica, nem alocados por uma necessidade qualquer, mas, ainda que habituais, repetidos e socialmente obrigatórios, sempre conservam o caráter de uma possibilidade, ou, dito de outra forma, eles sempre põem em jogo o próprio viver ${ }^{27}$.

\section{Considerações finais}

Devemos considerar através desta cartografia novas possibilidades de constituição de si no pênfigo e no cuidado ao sujeito com pênfigo, pois, na medida em que caminhamos por estas trilhas cartográficas nos deslocamos e começamos a promover novos modos de compor a relação com os sujeitos, novas formas de construir e de produzir um outro olhar, uma outra política ontológica.

Não se trata apenas de uma censura de práticas produzidas sobre o pênfigo, mas, da construção de uma aparelhagem destinada a produzir discursos, empenhada em dizer tudo o que há para se dizer, fazer aparecer sua verdade. Não simplesmente para condenar ou tolerar os sujeitos, mas para gerir, regular e fazer funcionar as práticas de cuidado segundo um padrão ótimo sobre estas minorias sociais.

Ao percorrermos as trilhas com o pênfigo nesta cartografia, considera-se que as práticas de sujeição e individualização se inscrevem sobre estes pacientes, em um perfil de bioidentidade e ecoidentidades, cujas características são reduzidas a padrões biomédicos de identidade e são co- 
locados a margem de práticas efetivas de atenção a saúde, pois as políticas em saúde que deveriam dar acesso são limitas a padrões populacionais.

E a pele como elemento físico nesta construção se registra, como a experiência primeira, não apenas pelas cicatrizes de pênfigo, mas por uma marca social de existência.

\section{Colaboradores}

DAR Silva trabalhou na concepção, análise e na redação final e AG Bernardes na metodologia. 


\section{Referências}

1. Cunha PR, Barraviera SRCS. Dermatoses bolhosas autoimunes. An Bras Dermatol 2009; 84(2):111-124.

2. Porro AM. Dermatoses imunobolhosas. In: Rotta O, organziador. Guias de medicina ambulatorial e hospitalar da Unifesp. Dermatologia: clínica, cirúrgica e cosmiátrica. Barueri: Manole; 2008. p. 259-266.

3. Azulay-Abulafia L, Azulay RD, Azulay DR. Buloses. In: Azulay RD, Azulay DR, organizadores. Dermatologia. Rio de Janeiro: Guanabara Koogan; 2004. p. 100-111.

4. Passos E, Kastrup V, Escóssia L. Pistas do método da cartografia: Pesquisa intervenção e produção de subjetividade. Porto Alegre: Sulina; 2010.

5. Passos E, Alvarez J. Cartografar é habitar um território existencial. In: Passos E, Kastrup V, Escóssia L. Pistas do método da cartografia: Pesquisa-intervenção e produção de subjetividade. Porto Alegre: Sulina; 2010.

6. Pigozi PL, Soares RAQ, Bigatto KRS, Santos SG, Santos LG, Machado AL. Revisão integrativa da cartografia na produção de pesquisas em enfermagem no Brasil. Saúde \& Transformação Social 2014; 5(3):75-82.

7. Deleuze G, Guattari F. Mil Platôs: Capitalismo e Esquizofrenia. Vol. 1. São Paulo: Editora 34; 1995.

8. Ferigato SH, Carvalho SR. Qualitative research, cartography and healthcare: connections. Interface (Botucatu) 2011; 15(38):663-675.

9. Mol A. Política Ontológica. Algumas ideias e várias perguntas. In: Nunes JA, Roque R, organizadores. Objectos impuros. Experiências em estudos sociais da ciência. Porto: Edições Afrontamento; 2007. p. 63-75

10. Aoki V, Hans-Filho G, Rivitti E, Diaz L, Ito LM. Perfil histórico da imunopatogenia do pênfigo foliáceo endêmico (fogo selvagem). An. Bras. Dermatologia 2005; 80(3):287- 292.

11. Deleuze G. Lógica do Sentido. São Paulo: Perspectiva 2000.

12. Foucault M. Microfísica do Poder. Rio de Janeiro: Graal; 1979.

13. Foucault M. A História da Loucura na Idade Clássica. São Paulo: Perspectiva; 1978.

14. Foucault M. O sujeito e o poder. In: Dreyfus H, Rabinow P. Michel Foucault, uma trajetória filosófica: para além do estruturalismo e da hermenêutica. Rio de Janeiro: Forense Universitária; 1995. p. 231-249.

15. Foucault M. A ordem do discurso. $21^{\text {a }}$ Ed. São Paulo: Edições Loyola; 2011.
16. Foucault M. História da Sexualidade Vol. II: O uso dos prazeres. Rio de Janeiro: Graal; 1984.

17. Birman J. A psicopatologia na pós-modernidade - As alquimias no mal-estar da atualidade. Revista Latinoamericana de Psicopatologia Fundamental 1999; 2(1):4046.

18. Foucault M. O Nascimento da Biopolítica. São Paulo: Martins Fontes; 2008

19. Brasil. Ministério da Saúde (MS). Diretrizes e recomendações para o cuidado integral de doenças crônicas não-transmissíveis: promoção da saúde, vigilância, prevenção e assistência. Brasília: MS; 2011.

20. Foucault M. Em defesa da sociedade. São Paulo: Martins Fontes; 1999.

21. Agamben G. Estado de Exceção. São Paulo: Boitempo; 2004.

22. Abegunde DO, Mathers CD, Adam T, Ortegon M, Strong K. The burden and costs of chronic diseases in low-income and middle-income countries. Lancet 2007; 370(9603):1929-1938.

23. World Health Organization (WHO). Global status report on noncommunicable diseases 2010. Geneva: WHO; 2011.

24. Ortega F, Zornelli R. Corpo em Evidência: a ciência e a redefinição do humano. Rio de Janeiro: Civilização Brasileira; 2010

25. Foucault M. História da Sexualidade Vol. III: O cuidado de si. Rio de Janeiro: Graal; 1985.

26. Foucault M. Os Anormais. São Paulo: Editora WMF Martins Fontes; 2001.

27. Agamben G. Homo Sacer: poder soberano e a vida nua. Belo Horizonte: Editora da UFMG; 2002.

Artigo apresentado em 01/06/2016

Aprovado em 17/08/2016

Versão final apresentada em 19/08/2016 